\title{
USE OF TECHNOLOGICAL ERRORS OF EQUIPMENT MANUFACTURING: DIGITAL SOUNDTRACKS AND DIGITAL RECORDING
}

\author{
Oleg Rybalskyi
}

National Academy of Internal Affairs, Kiev, Ukraine

\section{Valeriy Sereda}

Department of the National Police in the Lviv region, Lviv State University of Internal Affairs, Lviv, Ukraine

\section{Viktor Solovyov}

Volodymyr Dal East Ukrainian National University, Severodonetsk, Ukraine

\section{Zinaida Zhyvko}

Lviv State University of Internal Affairs, Lviv, Ukraine

\section{CMESTE}

JEL Category: L63

\begin{abstract}
The article deals with the theoretical bases of creating examination tools for the authenticity of digital soundtracks and identification of digital recording equipment based on a new direction. The purpose of this article is to show some theoretical considerations underlying our developed experimental examination tools. We believe that this will be done in the form of a series of articles, which are consistently showing the theoretical and experimental background of creating practical software products and techniques for authentication of digital soundtracks and identification of digital recording equipment, embedded in the practices of expert institutions of Ukraine. It is shown that parasite processes arising up in the elements of matrices and ADCS carry steady individual character. The use of these processes is offered for the receipt of identification signs, suitable for the use in examination of integrity and authenticity of the information contained in videogrammes. These signs carry fractal character, that it can be used for their selection from noises of images and subsequent statistical treatment. The direction is grounded on the use of stray parameters of the recording equipment, fixed in intrinsic noises of phonogram arising from technological errors of manufacturing equipment.
\end{abstract}

Keywords: authenticity, identification, digital recording, examination tools, digital soundtrack, examination, analog-to-digital conversion, fractality

Address of the corresponding author:

Oleg Rybalskyi

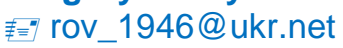

\section{INTRODUCTION}

Wide application of digital technology and digital recording of sound and images in all fields of 
human activity has resulted in the creation of examination tools to verify the authenticity of the materials of digital recording. Examination tools include expert software products and the methodology for conducting impact assessments. The difference of mathematical models describing the processes, which occur during recording sound and images, leads to separation of recording digital phonograms and digital images. In this article, we consider the modeling principles of examination tools for authentication of digital soundtracks and identification of digital recording equipment.

Scientists and specialists from different countries such as the United States, France, Britain, Russia, Brazil, Poland, Romania, and Spain deal with the development of examination tools of digital soundtracks. The diagnostic task of processing traces in digital soundtracks is solved by the methods of allocation of regular spectral components from the recorded signals and continuity of their phase (Korycki, R., 2010). However, in most proposed methods there are spectral components generated through electromagnetic network pickups for recording equipment. Nevertheless, in modern digital recording equipment, levels of such pickups in recordable digital signals are very small, and short-term (windowed) Fourier transform is used for their allocation. In fact, the expertise of these countries used one of the methods (that was created in the 70 s in the USSR) to verify the authenticity of information in analog soundtracks, not considering the specificities of digital recording of signals (Rybal'skiy, O.V.\& Zharikov, Yu. F., 2003). Tasks of identification of digital recording equipment are solved by comparison method of spectral composition of intrinsic noises allocated from the pauses between information signals (Cooper, A.J., 2008; Grigoras, C, 2011; Moon, C.B., Kim, H., \& Kim, B. M., 2014; Aggarwal, R., Singh, S., Roul, A. K. , \& Khanna, N., 2014; Garcia-Romero, D., \& Espy-Wilson, C. Y., 2010; Buchholz, R., Kraetzer, C., \& Dittmann, J., 2009; Panagakis, Y., \& Kotropoulos, C., 2012; Kotropoulos, C., 2013; Simeng Qi, Zheng Huang, Yan Li, \& Shaopei Shi, 2016). However, in these works, there is no analysis of constructive and technological peculiarities of digital recording equipment and the windowed Fourier transform is used for the allocation of identity features, but its resolving power is insufficient. The first such proposals appeared in publications issued in these countries in 2009, while in Ukraine this decision was proposed in 2003. Wavelet transform was used, and its resolving power resolution provides separation of individual features from noises characterizing digital recording equipment (Ribal's'kiy O.V., 2004).

Therefore, having read the works published by our international colleagues, we decided that we should provide them with theoretical and practical results of our work of last 12-15 years. In fact, in this field, we have created a new direction of constructing examination tools of digital soundtracks. We believe that this will be done in the form of a series of articles, which are consistently showing the theoretical and experimental background of creating practical software products and techniques for authentication of digital soundtracks and identification of digital recording equipment, embedded in the practices of expert institutions of Ukraine.

The purpose of this article is to show some theoretical considerations underlying our developed experimental examination tools.

\section{APPLYING STRAY PARAMETERS OF DIGITAL RECORDING EQUIPMENT}

As with any technology, digital recording equipment is designed and manufactured in control of its components. Therefore, digital recording equipment has its stray parameters. To apply these parameters for examination, it was necessary to consider different variations of constructing digital recording equipment, to find general nodes and blocks for all types of digital recording equipment and to define stray parameters of these nodes and blocks. You should choose those parameters, the influence of which on the signals creates identification signs, possessing persistent properties of individuality, repeatability and physical extraction of digital soundtracks from signals and/or intrinsic noises, in which they must be fixed (Rybal'skiy, O.V. \& Zharikov, Yu. F., 2003). Analysis of different kinds of constructions of digital recording equipment showed that sampling frequency generators are always applied in all types, analog-to-digital and 
digital-to-analog converters (ADCs and DACS, respectively). In addition, codecs of channel code and ECC codecs of various types, providing record digital information on the mobile carrier are used in digital magnetic recording equipment and instrument recording on optical discs. Moreover, data compression codecs are applied in digital recording equipment with the recording on the immobile carrier. The number of kinds and types of codecs is large enough, so it is no sense to consider them from the point of view of the use of stray parameters as identification signs. However, in the future, it should be noted that under integral assessment of any parameters of noise, their development can be used in identification.

Thus, regardless of the type of carrier (mobile or stationary), ADCs and DACS and sampling frequency generators are always used in any type of digital recording equipment. So, stray parameters of these nodes and blocks were considered. In the beginning, we studied structural features and stray parameters of different types of ADCs and then we found that level quantizer was used in any of them. This node represents the interest from the point of view of identification signs. So, let's look at it in more detail.

Level quantizer represents an $R-2 R$ resistive matrix. It is intended to establish the weight of each bit of ADC (the principle of analog-to-digital conversion is not considered in this work, but it should be noted that this process consists of two operations - analog signal sampling temporally and quantization of obtained samples by the level). The transfer characteristic of the level quantizer is determined by its static characteristic, more generally shown in Figure 1.

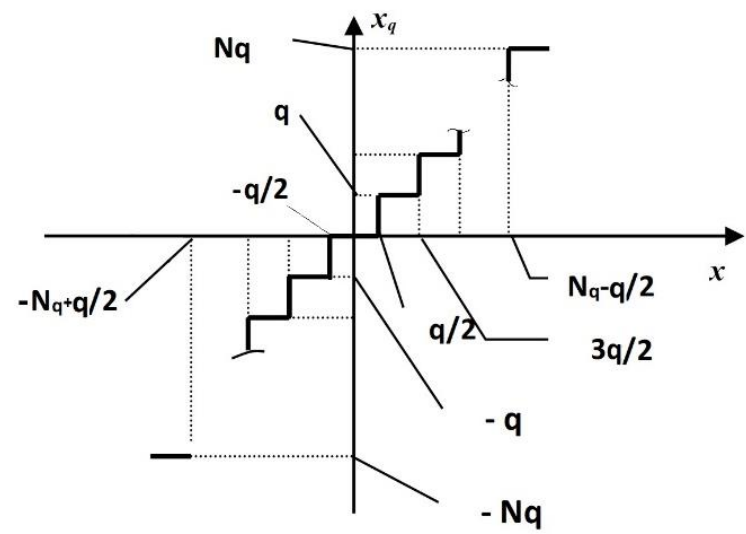

Fig.1. Quantizer characteristic
The total error of $A D C$ is defined as

$\bar{\delta}_{A D C s}^{2}=\bar{\delta}_{0}^{2}+\bar{\delta}_{d y n}^{2}+\bar{\delta}_{q}^{2}$,

where:

$\bar{\delta}_{0}^{2}=\frac{\Delta_{0}^{2}}{U_{o n}^{2}} \quad-$ mean square of the static error

of ADC, defined by the instability of time and temperature, intrinsic noise of analog nodes, inaccuracy of technological manufacturing of individual components, in particular, a quantizer;

$\bar{\delta}_{d y n}^{2}=\frac{\Delta_{d y n}^{2}}{U_{o л}^{2}} \quad-$ mean square of dynamic error of ADC;

$\bar{\delta}_{q}^{2}=\frac{q^{2}}{12} \quad$ - dispersion of quantization error by level (for a uniformly distributed random quantity),

where

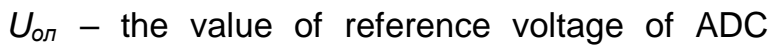
(Rybal'skiy, O.V. \& Zharikov, Yu. F., 2003; Rybal'skiy, O.V., 2004).

Consider these errors in terms of their use in the examination during conducting identification research of digital recording equipment and checking the originality and integrity of digital soundtracks.

We are not interested in dynamic error for two reasons:

- Firstly, in ADC, using the sample and hold circuit, this error is virtually non-existent (namely, such ADCs are used in digital recording equipment);

- Secondly, it is impossible to determine it in the examined soundtrack because of the unknown original form of the input signal to convert it.

The variance of quantization error by level is not interesting for an expert, because it is determined only by the level of the least significant bit (LSB) and make fluctuations of this level relative to the zero value of the signal.

However, the static error of ADCs and DACS, which includes the inaccuracy of technological manufacture of individual nodes, level quantizer, is of interest for its use in expert investigations. 
Therefore, this error should be considered in detail. Defects of manufacturing level quantizer are important among the errors of a static characteristic of ADC (Huijbregtse, M., \& Geradts, Z., 2009; Brixen, E., 2011)., which can be potentially used in the examination, they are:

- differential nonlinearity (DNL) $\delta_{l d}$, the deviation between two analog values corresponding to adjacent input digital values. It is an important specification for measuring the error in DAC; the accuracy of DAC is mainly determined by this specification. Ideally, any two adjacent digital codes correspond to output analog voltages that are exactly one LSB apart. Differential non-linearity greater than \pm 1 LSB may lead to a non-monotonic transfer function in DAC

- non-monotonic form of static characteristic $\delta_{n m}$ - the deviation of increment signs of the response and the impact on at least one of its sections (see Fig. 2).

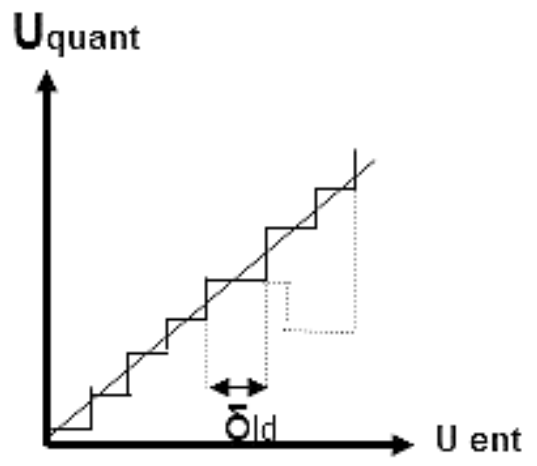

Fig. 2. Differential non-linearity and a nonmonotonous section of a static characteristic of quantization

Certainly, that all these technological defects will be revealed only in the output signals. Therefore, you should consider the system of analog-todigital conversion as a serious circuit of ADCs and DACs. To consider the circuitry of ADCs and DACs makes no sense because they are considered in detail in many works, such as in the works (Rybal'skiy, O.V. \& Zharikov, Yu. F., 2003; Rybal'skiy, O.V., 2004). Note, however, that digital recording equipment usually uses $A D C$ of bitwise balancing, while sampling of the original analog signal is used by the sample and hold circuit.

Considering the model of signal passage through the system of analog-to-digital conversion, we note that digital input signals of DAC enter in accordance with the input digital word in the parallel code with a frequency, equal to the sampling rate. The stepwise analog signal is formed on its output, and it is equal to the sum of the "weights" of all bits of the input code. You can write analog output signal of DAC analytically (Baranov L.A.,1990) as

$$
U=\sum_{i=0}^{n-1} a_{i} 2^{i} U_{\text {on }},
$$

where

$U \quad-$ analog value, the result of conversion;

$U_{o n}$ - reference voltage indicating least significant bit (LSB);

$a_{i} \quad$ - weighting factors determined by bits of the binary code.

Thus, the instantaneous value of output signal of each sample of DAC is the sum of bit's "weight" of the input code, in proportion to that R-2R matrix divides the value of the reference voltage.

Therefore, if analog input signal $x(t)$ is supplied to the input of digital recording equipment, the level quantizer of which has differential nonlinearity or non-monotonic form of static characteristic, the output signal $y(t)$ (with the assumption that the digital recording equipment transmits digital signals without loss) can be written as

$$
y(t)=y_{1}(t)+y_{2}(t)=\sum_{i=0}^{k} a_{i} 2^{i} U_{\text {on }}+\sum_{k+1}^{n-1} a_{i} 2^{i} U_{\text {on }}=
$$$$
a_{k+1} 2^{k+1} U_{\text {on }}+\sum_{i=0}^{k} a_{i} 2^{i} U_{\text {on }}+\sum_{k+2}^{n-1} a_{i} 2^{i} U_{\text {on }}
$$

where:

$y_{1}(t)$ - analog signal before the appearance of a non-monotonic form of static characteristic,

$y_{2}(t)$-analog signal after the appearance of a non-monotonic form of static characteristic,

$k$ - quantization level, until which nonmonotonic form of the static characteristic is missing,

$k+1$ - following $k$ quantization level with a nonmonotonic form of static characteristic,

$k+2$ - quantization level following the level, on which there is a non-monotonic form of static characteristic. 
It should be noted, however, that the quantization level $k+1$ by its value is equal to the value of $k$ level as demonstrated in (3). That is, the quantization level in the interval answering to the quantization level $k+1$ is equal to $k$ level, which must match the previous interval of quantization (limit value of differential nonlinearity (DNL) or minimum variant of value of non-monotonic form of static characteristic, although it can exceed the value of the level of least significant bit (LSB)).

You can see (3) that if there is level quantizer of the section with differential nonlinearity or nonmonotonic form of static characteristic, ADC code will be changed under direct conversion. Accordingly, the output signal $y(t)$ at the outlet of the system of analog-to-digital conversion will have distortions of the form (e.g. signal burst), that will certainly lead to a change in the spectral composition of the output signal, and it will contain the frequency corresponding to the frequency of ADC conversion.

Thus, there is an opportunity to develop methodology and tools for identification of digital recording equipment and authentication of digital soundtracks with such distortions, if you show that the non-monotonic form of the static characteristic is individual identification sign for each individual type of level quantizer.

It is easy to calculate the probability of differential nonlinearity or non-monotonic form of the static characteristic for particular quantization level: it is $1 / 65535$ for 16-bit conversion (of course, if this converter has a non-monotonic form of static characteristic and it is available in almost all converters). Therefore, the matching probability of sections with differential nonlinearity or nonmonotonic form of the static characteristic for two different types of level quantizer would be approximately $2.3 \cdot 10^{-10}$, that is, differential nonlinearity or non-monotonic form of static characteristic are stable individual identification signs of each specific type of ADC and DAC.

Besides differential nonlinearity and nonmonotonic form of static characteristic, the true value of sampling frequency has individuality, since the frequency generated by any generator, is always different from the rated value. This influence affects when rerecording signals via analog output/input from one digital recording equipment to another and manifests itself in the appearance of additional frequency components. The influence of the difference of true sampling frequency when rerecording is considered in many our works, for example, in the works (Rybal'skiy, O.V. \& Zharikov, Yu. F., 2003; Rybal'skiy, O.V., 2004). It seems inappropriate to consider these questions here.

When processing signals of digital soundtracks in sound editors, the most difficult way to detect traces of processing is the compilation of the new content of the signals recorded by one digital recording equipment. This is due to the equal nature of intrinsic noises, fixed in digital soundtracks. The most difficult case of the compilation is cut and permutation of the fragments in one digital soundtrack. However, when such processing extra spectral components appear in the fragments of the digital soundtrack (Rybal'skiy O.V., Solov'yev V.I., \& Zhuravel' V.V., 2016).

Conducted researches were presented in the form of a theory of identifying traces of the digital processing of soundtracks (Ribal's'kiy O.V., 2004; Rybal'skiy O.V., 2006). The main provisions of this theory are shown below.

Provision 1. The probability of coincidence of sampling frequency devices involved in the digital processing of soundtracks is negligible.

Provision 2. The probability of coincidence of quantization levels with technological defects of quantizer devices involved in the digital processing of soundtracks is negligible.

Provision 3. External interposition and modification of the information contained in digital soundtracks are possible when using at least two different digital devices.

Provision 4. Traces of digital processing of the soundtrack are revealed as form distortions and, therefore, the spectrum of analog signals received on the analog output of equipment when record playing back of analog signals of the soundtrack, processed in digital form.

Provision 5. In the spectrum of the digitally processed analog signal, if you are using operations of sampling fragments with their subsequent compilation for sound editing, there are distortions, caused by the influence of strobe. 
Provision 6. The guaranteed reveal of distortions of the form and spectrum of processed signals contained in the soundtrack is provided by the use of microwave time-frequency analysis. To build this analyzer it is advisable to use a complex function of Morlet.

Provision 7. Sources of the appearance of distortions of the form and spectrum of signals during digital processing of soundtracks are:

- noncoincidence of allocation of different devices involved in processing with the static characteristic of the level quantizer of ADC and DAC, as well as quantization levels with technological defects;

- the discrepancy of true values of frequencies in clock generators of devices participating in the process;

- sampling to cut out fragments of the soundtrack for sound editing by the method of compilation of the new one from fragments ("stitching") in the computer.

Provision 8. The informative sign of digital processing traces of soundtracks is the regularity of inevitable increasing distortions of form and the number of spectral components of signals reproduced from the digitally processed soundtrack relative to the level of these distortions and the number of the components selected from similar signals reproduced from the soundtrack, which has not been subject to this process (Ribal's'kiy O. V., 2004; Rybal'skiy O. V., 2006).

The purpose of all these theoretical researches is aimed at capability check of the creation of automated examination tools for examination of digital recording equipment and digital soundtracks. The result of these researches was the formation of a new direction for the creation of such examination tools - the use of stray parameters of the recording equipment, fixed in the signals of intrinsic noises of phonograms. Later, in the process of developing examination tools for digital recording equipment and digital soundtracks, the fractal nature of intrinsic noises of digital soundtracks was set up, it has individual character and it is conditioned by the influence of stray parameters of digital recording equipment (Rybal'skiy O.V., Solov'yev, V.I., \& Zhuravel' V.V., 2013).

Based on the conducted theoretical researches, experimental samples of the specialized software and methods of examination were developed. Features of constructing the examination tools are discussed in the following articles.

\section{CONCLUSIONS}

The analysis of technological inaccuracies of manufacturing nodes and blocks (stray parameters) of digital recording equipment, in particular, ADC and DACs-level quantizers, showed their influence on the appearance of identification signs in intrinsic noises of recording equipment that has individual character.

It is shown that such identification signs can be used for identification and diagnostic expert investigations of digital recording equipment and digital soundtracks.

It is proved that the use of stray parameters of the recording equipment is a new direction of creating the examination tools. It is proposed to develop examination tools based on this direction. Methods of constructing such tools will be considered in the subsequent articles.

\section{WORKS CITED}

Aggarwal, R., Singh, S., Roul, A. K., Khanna, N. (2014). Cellphone identification using noise estimates from recorded audio. 2014 International Conference on Communications and Signal Processing (ICCSP). IEEE. pp. 1218-1222.

Baranov, L.A. (1990). Kvantovaniye po urovnyu i vremennaya diskretizatsiya $v$ tsifrovykh sistemakh upravleniya. Moscow: Energoatomizdat, pp. 304.

Brixen, E. (2011). Audio Metering Measurements, Standards and Practices: Second Edition. United States: Elsevier.

Buchholz, R., Kraetzer, C., Dittmann, J. (2009). Microphone classification using Fourier coefficients. Information Hiding, Springer, pp. 235-246. 
Cooper, A.J. (2008). Detection of Copies of Digital Audio Recordings Produced Using Analogue Interfacing. International Journal of Speech, Language, and the Law, 15(1), 67-95.

Cooper, A.J. (2009). An automated approach to the Electric Network Frequency (ENF) criterionTheory and practice. International Journal of Speech-Language and the Law, 16, p. 193-218.

Garcia-Romero, D., \& Espy-Wilson, C.Y. (2010). Espy-Wilson, Automatic acquisition device identification from speech recordings, in Acoustics Speech and Signal Processing (ICASSP), 2010 IEEE International Conference on, IEEE, 2010, pp. 1806-1809.

Grigoras, C., et al. (2011, Oct 22-23). Advances in ENF Database Configuration for Forensic Authentication of Digital Media. Presented at the 131st convention of the Audio Engineering Society, New York, USA.

Grigoras, C. (2010, June 17-19). Statistical Tools for Multimedia Forensics. Presented at the 39th AES International Conference Audio Forensics - Practices and Challenges, Hillerod, Denmark.

Huijbregtse, M., \& Geradts, Z. (2009). Using the ENF criterion for determining the time of recording of short digital audio recordings. Computational Forensics, p. 116-124.

Jenkins, C. W. (2011). An Investigative Approach to Configuring Forensic Electric Network Frequency Databases. Master's Thesis, University of Colorado Denver.

Korycki, R. (2010). Methods of time-frequency analysis in authentication of digital audio recordings, Intl Journal of Electronics and Telecommunications, 56(3), 257-262.

Kotropoulos, C. (2013). Telephone handset identification using sparse representations of spectral feature sketches, 2013 International Workshop on Biometrics and Forensics (IWBF), IEEE, pp. 1-4.

Moon, C.-B., Kim, H., \& Kim, B. M. (2014). Audio recorder identification using reduced noise features. Ubiquitous Information Technologies and Applications, Springer. pp. 35-42.

Nicolalde, D.P. \& Apolinario, J. A. (2009). Evaluating digital audio authenticity with spectral distances and ENF phase change, Proc. IEEE International Conference on Acoustics, Speech and Signal Processing, p. 1417-1420.

Nicolalde, D.P., Apolinario, J.A., \& Biscainho, L.W.P (2010). Audio authenticity: Detecting ENF discontinuity with high precision phase analysis. IEEE Transactions on Information Forensics and Security, 5, p. 534-543.

Panagakis, Y., C. (2012). Kotropoulos, Automatic telephone handset identification by the sparse representation of random spectral features. Proceedings of the on Multimedia and security, ACM, pp. 91-96.

Rappaport D.L. (2010). Establishing a Standard for Digital Audio Authenticity: A Critical Analysis of Tools, Methodologies, and Challenges Thesis directed by Catalin Grigoras. Retrieved from: http://aquarius.ime.eb.br/ apolin/papers/IEEETIFS2010Daniel.pdf http://ieeexplore.ieee.org/

Rybal'skiy O.V. (2006). Osnovnyye polozheniya teorii vyyavleniya sledov tsifrovoy obrabotki fonogramm i osobennosti yeye programmnoy i metodicheskoy realizatsii $v$ ekspertize materialov i sredstv videozvukozapisi. Zakhist ínformatsii, (1), pp.71-76.

Rybal'skiy O.V., Solov'yev, V.I. , Zhuravel', V.V. (2016). Sledy montazha v tsifrovykh fonogrammakh, vypolnennogo sposobom vyrezaniya i perestanovki fragmentov. Reestratsiya, zberígannya í obrobka danikh, 18(1). pp. 32-41. 
Rybal'skiy O. V., Zharikov, Yu. F. (2003). Sovremennyye metody proverki autentichnosti magnitnykh fonogramm $v$ sudebno-akusticheskoy ekspertize. Kiev: Nats. akad. vnutr. sprav Ukraini, p. 300 .

Rybal's'kiy O.V. (2004). Zastosuvannya veyvlet-analízu dlya viyavlennya slidiv tsifrovoi obrobki analogovikh í tsifrovikh fonogram u sudovo-akustichníy yekspertizi. Kiev: Nats. akad. vnutr. sprav Ukraini, p. 167.

Rybal'skiy O.V. (2006). K voprosu o fraktal'nosti analogovykh signalov, podvergnutykh tsifrovoy obrabotke. Vísnik Skhidnoukrains'kogo natsíonal'nogo uníversitetu im V. Dalya. 9(1). p.2125 .

Simeng Qi, Zheng Huang, Yan Li, Shaopei Shi. (2016). Audio Recording Device Identification Based on Deep Learning. IEEE International Conference on Signal and Image Processing (ICSIP), Beijing, China. doi: 10.1109/SIPROCESS.2016.7888298 Retrieved from https://ieeexplore.ieee.org/document/7888298/

Zhuravel' V.V., Rybal'skiy O.V., Solov'yev V.I. (2013). Strukturirovannost' signalogramm i universal'nost' fraktal'nogo podkhoda pri sozdanii instrumentariya fonoskopicheskoy ekspertizy. Informatika ta matematichní metodi v modelyuvanní, 3(3), pp. 225-232.

Received for publication: $\quad 09.02 .2018$

Revision received: $\quad 28.05 .2018$

Accepted for publication: $\quad 07.06 .2018$

\section{How to cite this article?}

Style - APA Sixth Edition:

Rybalskyi, O., Sereda, V., Solovyov, V., \& Zhyvko, Z. (2018, July 15). Use of Technological Errors of Equipment Manufacturing: Digital Soundtracks and Digital Recording. (Z. Cekerevac, Ed.) MEST Journal, 6(2), 109-116. doi:10.12709/mest.06.06.02.14

Style - Chicago Sixteenth Edition:

Rybalskyi, Oleg, Valeriy Sereda, Viktor Solovyov, and Zinaida Zhyvko. 2018. "Use of Technological Errors of Equipment Manufacturing: Digital Soundtracks and Digital Recording." Edited by Zoran Cekerevac. MEST Journal (MESTE) 6 (2): 109-116. doi:10.12709/mest.06.06.02.14.

Style - GOST Name Sort:

Rybalskyi Oleg [et al.] Use of Technological Errors of Equipment Manufacturing: Digital Soundtracks and Digital Recording [Journal] // MEST Journal / ed. Cekerevac Zoran. - Toronto : MESTE, July 15, 2018. - 2 : Vol. 6. - pp. 109-116.

Style - Harvard Anglia:

Rybalskyi, O., Sereda, V., Solovyov, V. \& Zhyvko, Z., 2018. Use of Technological Errors of Equipment Manufacturing: Digital Soundtracks and Digital Recording. MEST Journal, 15 July, 6(2), pp. 109-116.

Style - ISO 690 Numerical Reference:

Use of Technological Errors of Equipment Manufacturing: Digital Soundtracks and Digital Recording. Rybalskyi, Oleg, et al. [ed.] Zoran Cekerevac. 2, Toronto : MESTE, July 15, 2018, MEST Journal, Vol. 6, pp. 109-116. 